\title{
Moving beyond 'meaning': Gorillas combine gestures into sequences for creative display
}

\author{
Joanne E. Tanner ${ }^{\mathrm{a}, *}$, Marcus Perlman ${ }^{\mathrm{b}}$ \\ a Scottish Primate Research Group, UK \\ ${ }^{\mathrm{b}}$ Department of Cognitive E' Information Sciences, University of California, 5200 North Lake Rd., Merced, CA 95343, USA
}

\section{A R T I C L E I N F O}

\section{Article history:}

Available online $\mathrm{xxx}$

\section{Keywords:}

Language origins

Music origins

Multimodal communication

Gesture sequences

Gorilla

Great ape

\begin{abstract}
A B S T R A C T
The great apes produce gestures intentionally and flexibly, and sometimes they combine their gestures into sequences, producing two or more gestures in close succession. We reevaluate previous findings related to ape gesture sequences and present qualitative analysis of videotaped gorilla interaction. We present evidence that gorillas produce at least two different kinds of gesture sequences: some sequences are largely composed of gestures that depict motion in an iconic manner, typically requesting particular action by the partner; others are multimodal and contain gestures - often percussive in nature - that are performed in situations of play or display. Display sequences seem to primarily exhibit the performer's emotional state and physical fitness but have no immediate functional goal. Analysis reveals that some gorilla play and display sequences can be 1) organized hierarchically into longer bouts and repetitions; 2) innovative and individualized, incorporating objects and environmental features; and 3) highly interactive between partners. It is illuminating to look beyond 'meaning' in the conventional linguistic sense and look at the possibility that characteristics of music and dance, as well as those of language, are included in the gesturing of apes.
\end{abstract}

(c) 2016 Elsevier Ltd. All rights reserved.

\section{Introduction}

Humans possess an unprecedented ability to communicate complex meanings by combining words (and signs) into the grammatical sequences of language. Thus scholars interested in the origins of language have taken note of how our great ape relatives - chimpanzees and bonobos, gorillas, and orangutans - are also naturally ${ }^{1}$ inclined to combine gestures into sequences (Genty and Byrne, 2010; Hobaiter and Byrne, 2011; Liebal et al., 2004; Tempelmann and Liebal, 2012; Tanner, 2004; Tomasello et al., 1994). However, these studies have generally failed to find much evidence of anything like compositional semantics in ape sequences. Thus, in this critical respect, ape sequences do not appear to be very languagelike.

\footnotetext{
* Corresponding author. 3071 Dover Drive, Santa Cruz, CA 95065, USA.

E-mail address: gorilvr@cruzio.com (J.E. Tanner).

1 "Naturally" indicates our focus on apes outside of intensive human training and enculturation, particularly the Ape Sign Language research projects (Fouts and Mills, 1997; Greenfield et al., 2008; Patterson and Linden, 1981; Terrace, 1979). The literature on these controversial studies is sharply divided concerning the semantic and syntactic status of utterances produced by language-trained apes.
} 
In this paper, we offer a fresh perspective on the gesture sequences produced by apes and their significance in the evolution of human communication. Perhaps, previous studies, in their linguistic preoccupation with grammar and meaning, have missed the potential homology between the gesture sequences of apes and human music. In addition to outstanding linguistic skills, humans also possess a special ability to combine audible and visible "gestures" into the multimodal compositions of song and dance. Might the sequences of gestures produced by apes bear any likeness to musical performances?

To shed light on this possibility, we begin with the crucial question of why apes combine gestures into sequences. First, we sort through the inconclusive mix of answers from previous research. Stemming from this review, we propose that some gesture sequences - particularly those composed largely of audible, percussive gestures - are more aptly understood as creative display, rather than "meaningful" communication intended to achieve an immediate goal. We examine this hypothesis through detailed, qualitative analysis of four video-recorded examples of display-like gesture and action sequences produced by western lowland gorillas at the San Francisco Zoo (along with one contrasting example). Our analysis reveals that these sequences show impressive versatility in several respects. For one, they show hierarchical organization in the ways that their component gestures and other actions are arranged into longer performances and repetitions. We also find that displays can be innovative and individualized, making use of the particular affordances granted by the environment. And in some cases, they can be highly interactive performances that are jointly constructed between partners. Ultimately, we argue that these qualities - hierarchical organization, innovation, and interactivity, as well as the percussive medium - draw an intriguing comparison to musical expression.

\subsection{Why do great apes combine gestures into sequences?}

Gesture is recognized to be an important channel of communication for the great apes (Call and Tomasello, 2007). Indeed, apes exhibit a notable degree of social-cognitive sophistication with their gesturing. For example, they use gestures flexibly and intentionally, communicating across a variety of contexts to achieve a variety of goals (see Byrne, 2016; Call and Tomasello, 2007, for reviews). When using gestures, apes are sensitive to the attentional state of their audience, producing more audible and tactile gestures when lacking the visual attention of their partner (Leavens et al., 2004, 2010; Tanner and Byrne, 1996). And although the ontogeny of gesture repertoires is debated for populations outside of human influence (e.g. Call and Tomasello, 2007; Hobaiter and Byrne, 2011; Perlman et al., 2012), when taught or influenced by humans, apes can acquire large inventories of new gestures, which can number on the order of one hundred or more (Fouts and Mills, 1997; Miles, 1990; Tanner et al., 2006; Terrace, 1979).

When great apes gesture with each other, they are often inclined to use gestures in sequences, stringing together two or more in quick succession. Indeed, a substantial proportion of the gestures apes produce occurs in sequences: between $20 \%$ and $40 \%$ depending on the study and species (see Table 1 ). Some of these sequences involve the repetition of the same gesture, but often they are composed of various gestures. Sequences may range considerably in length, extending to as many as 11 gestures (Hobaiter and Byrne, 2011), although this depends on the particular criteria used to define a "sequence."

Sequences are typically characterized as a connected string of gestures, occurring in quick succession as a single communicative act. However, in different operating definitions, researchers have designated different maximum time intervals between gestures. One frequently used criterion is that sequences are comprised of gestures occurring without any pause longer than $1 \mathrm{~s}$ between the end of one gesture and the onset of another (cf. Genty and Byrne, 2010; Hobaiter and Byrne, 2011; Tanner, 2004). However, another study defined sequences to include gestures spaced up to 5 s apart (Liebal et al., 2004). And Hobaiter and Byrne (2011) used the term 'bout' for successive gestures that were produced, not within a particular time interval of each other, but together within a period bounded by the cessation of gesturing. In the present paper, we recognize that the lack of agreement on terms affects findings on sequences and bouts, and when it is relevant, we note the particular inter-gesture intervals.

Fundamental to understanding ape gesture sequences - and their evolutionary relationship to human communication - is the question of why apes produce them. Several studies have investigated this question, but have come to a number of different answers (see Table 1). One general point of consensus is that there is little evidence that apes "naturally" (i.e., without language training; see Footnote 1) combine gestures together in any fashion resembling the grammatical combination of words into sentences (Genty and Byrne, 2010; Tomasello et al., 1994; but see Tanner, 2004). Aside from pragmatic goals like first getting a partner's attention, the choice of different gestures does not appear to result in new "meanings" along the lines of any kind of compositional semantics (Liebal et al., 2004). Thus it does not appear that apes use gesture sequences to communicate complex messages, as with human language. However, researchers have proposed that ape gesture sequences may serve several other functions in communication.

A baseline possibility is that apes produce successions of gestures simply as a manifestation of emotional arousal. For example, Tempelmann and Liebal (2012) observed 86 sequences performed by 16 captive orangutans of varied age and sex at two zoos. They found that the gesture combinations produced by the subjects did not appear to be directed towards any particular communicative goal. Most sequences occurred during play and continued regardless of the recipient's response, suggesting that the production of multiple gestures in close succession reflected arousal during play. 
Table 1

Comparison of studies of gesture sequences.

\begin{tabular}{|c|c|c|c|c|c|c|c|}
\hline Study & $\begin{array}{l}\text { Species and } \\
\text { number of } \\
\text { subjects }\end{array}$ & $\begin{array}{l}\text { Study population } \\
\text { and setting }\end{array}$ & $\begin{array}{l}\text { Criteria for phrase } \\
\text { or sequence }\end{array}$ & $\begin{array}{l}\text { Percent of } \\
\text { gestures } \\
\text { produced } \\
\text { in } \\
\text { sequences }\end{array}$ & $\begin{array}{l}\text { Length of } \\
\text { sequences }\end{array}$ & Study emphasis & $\begin{array}{l}\text { Main findings on } \\
\text { function }\end{array}$ \\
\hline $\begin{array}{l}\text { Tomasello et al. } \\
\text { (1994) }\end{array}$ & $\begin{array}{l}\text { Chimpanzee } \\
8\end{array}$ & $\begin{array}{l}\text { Captive research } \\
\text { group, Yerkes Field } \\
\text { Station, Atlanta GA }\end{array}$ & $\begin{array}{l}\text { "Multiple gestures } \\
\text { to the same end in a } \\
\text { single event" }\end{array}$ & $30 \%$ & $1-3$ gestures & $\begin{array}{l}\text { How gestures are } \\
\text { combined in a } \\
\text { single act, and } \\
\text { whether this opens } \\
\text { up new } \\
\text { communicative } \\
\text { functions }\end{array}$ & $\begin{array}{l}\text { Persistence to elicit } \\
\text { response from } \\
\text { partner, especially } \\
\text { play; possible } \\
\text { attention-getters }\end{array}$ \\
\hline Tanner (2004) & $\begin{array}{l}\text { Western } \\
\text { Lowland gorilla } \\
2\end{array}$ & $\begin{array}{l}\text { Zoo, San Francisco, } \\
\text { CA }\end{array}$ & $\begin{array}{l}\text { Interval of }<1 \mathrm{~s} \\
\text { between gestures }\end{array}$ & $35 \%$ & 2-8 gestures & $\begin{array}{l}\text { Pragmatic } \\
\text { functions of } \\
\text { gestures within } \\
\text { sequences } \\
\text { (attention getters, } \\
\text { directives, } \\
\text { negatives) }\end{array}$ & $\begin{array}{l}\text { Various functions: } \\
\text { gaining the } \\
\text { partner's attention, } \\
\text { directing } \\
\text { movement and } \\
\text { location, and } \\
\text { cutting off the } \\
\text { interaction; } \\
\text { sometimes occur in } \\
\text { exchanges between } \\
\text { gorillas }\end{array}$ \\
\hline Liebal et al. (2004) & $\begin{array}{l}\text { Chimpanzee } \\
19\end{array}$ & $\begin{array}{l}\text { Captive research } \\
\text { group, Yerkes Field } \\
\text { Station, Atlanta GA }\end{array}$ & $\begin{array}{l}\text { Interval of }<5 \mathrm{~s} \\
\text { between gestures }\end{array}$ & $33 \%$ & 2-39 gestures & $\begin{array}{l}\text { Reason for } \\
\text { sequences: criteria } \\
\text { of use of tactile } \\
\text { versus visual } \\
\text { modalities }\end{array}$ & $\begin{array}{l}\text { Persistence in } \\
\text { eliciting response } \\
\text { from partner, } \\
\text { especially play }\end{array}$ \\
\hline $\begin{array}{l}\text { Genty and Byrne } \\
\text { (2010) }\end{array}$ & $\begin{array}{l}\text { Western } \\
\text { lowland gorilla } \\
30 \text { captive } \\
130 \text { wild }\end{array}$ & $\begin{array}{l}3 \text { zoos (European) } \\
\text { and one wild group } \\
\text { at Mbeli Bai, Congo }\end{array}$ & $\begin{array}{l}\text { Interval of }<1 \mathrm{~s} \\
\text { between gestures }\end{array}$ & $35 \%$ & $2-8$ gestures & $\begin{array}{l}\text { Reason for } \\
\text { sequence use } \\
\text { versus single } \\
\text { gestures }\end{array}$ & $\begin{array}{l}\text { Regulation of play; } \\
\text { no evidence that } \\
\text { they increase } \\
\text { communication } \\
\text { success }\end{array}$ \\
\hline $\begin{array}{l}\text { Hobaiter and Byrne } \\
\text { (2011) }\end{array}$ & $\begin{array}{l}\text { Chimpanzee } \\
82\end{array}$ & $\begin{array}{l}\text { Wild, Budongo, } \\
\text { Uganda }\end{array}$ & $\begin{array}{l}\text { Interval of }<1 \mathrm{~s} \\
\text { between gestures; } \\
\text { longer intervals } \\
\text { called 'bouts' }\end{array}$ & $39 \%$ & 2-11 gestures & $\begin{array}{l}\text { "Success rates" of } \\
\text { sequences versus } \\
\text { single gestures; } \\
\text { influence of age on } \\
\text { sequence use }\end{array}$ & $\begin{array}{l}\text { Learn which } \\
\text { gestures are most } \\
\text { effective in order to } \\
\text { tune repertoire }\end{array}$ \\
\hline Roberts et al. (2013) & $\begin{array}{l}\text { Chimpanzee } \\
12\end{array}$ & $\begin{array}{l}\text { Wild, Budongo, } \\
\text { Uganda }\end{array}$ & $\begin{array}{l}\text { All gestures made } \\
\text { within } 30 \mathrm{~s} \text { (before } \\
\text { and after) of a } \\
\text { response by a } \\
\text { recipient }\end{array}$ & $26 \%$ & $2-5$ gestures & $\begin{array}{l}\text { Response } \\
\text { congruency to } \\
\text { sequence } \\
\text { production; } \\
\text { communicative } \\
\text { persistence to } \\
\text { "goals" }\end{array}$ & $\begin{array}{l}\text { Increase } \\
\text { communication } \\
\text { success by } \\
\text { strategically } \\
\text { modifying gestures } \\
\text { depending on } \\
\text { partner's } \\
\text { understanding }\end{array}$ \\
\hline $\begin{array}{l}\text { Tempelmann and } \\
\text { Liebal (2012) }\end{array}$ & $\begin{array}{l}\text { Orangutan } \\
16\end{array}$ & 2 zoos (European) & $\begin{array}{l}\text { Interval of }<5 \mathrm{~s} \\
\text { between gestures }\end{array}$ & $20 \%$ & $2-8$ gestures & $\begin{array}{l}\text { Reason for } \\
\text { sequence use } \\
\text { versus single } \\
\text { gestures }\end{array}$ & $\begin{array}{l}\text { Reflect arousal } \\
\text { during play }\end{array}$ \\
\hline
\end{tabular}

However, other studies have found evidence that apes do sometimes produce multiple gestures to improve the success of communication (Cartmill and Byrne, 2007; Leavens et al., 2005; Liebal et al., 2004; Tomasello et al., 1994). In some cases, apes appear to accomplish communicative goals (e.g. initiate play, obtain food, direct a partner's movement) through sheer persistence in their gesturing. A longitudinal study with a group of captive chimpanzees found that $30 \%$ of their gestures occurred in combinations that included repetitions of the same gesture and also mixes of two and three different gestures (Tomasello et al., 1994). Almost all of these combinations were produced when an individual gestured for play. When an initial gesture did not elicit the desired response from a partner, the gesturer persisted with the same or different gestures. Subsequent work with the same chimpanzees, this time applying a $5 \mathrm{~s}$ inter-gesture interval, found similar patterns in gesture combinations (Liebal et al., 2004). Again play was the most frequent context, and many of the sequences (38.6\%) included repetitions of a single, often tactile gesture. Sequences were typically used when there was a lack of response to an initial gesture, thus showing persistence in eliciting a response from the partner.

There is also evidence that apes elaborate on their gestures to obtain a particular goal. For example, one experiment examined how captive chimpanzees responded before and after delivery of a desirable food item, half that item, or a less 
desirable item (Leavens et al., 2005). The results showed that, when receiving just the half or undesirable item, the subjects elaborated their communication, using a larger number of different gestures in an effort to obtain the most desirable item. In a similar experimental setup, orangutans appeared to modify their gestures based on a communication partner's level of understanding (Cartmill and Byrne, 2007). When receiving a desirable full serving, the orangutans ceased gesturing. But when receiving only half of it, they persisted in signaling to the experimenter, but narrowed their range of signals and used them repeatedly. And when receiving the undesirable food - indicating that the experimenter had completely misunderstood the request - the orangutans elaborated their range of gestures and avoided failed types. Thus they appeared to use successive gestures to indicate prior misunderstanding and to make their goals more clear. Comparable use of gesture sequences was also observed in wild chimpanzees in the Budongo Forest in Uganda (Roberts et al., 2013). The study examined the chimpanzees' gesture sequences with respect to their "goals," which were determined as the most frequent response to the particular gesture. In 20 observations of sequences produced by twelve adults Roberts et al. found that chimpanzees repeated the same gesture when a response partly matched a goal, and subsequently tried different gestures when the initial response was incongruent. Overall, the use of gesture sequences increased the success rate to a presumed goal.

A few studies have examined whether apes might use a conspicuously audible gesture or a tactile gesture to gain the visual attention of a non-attending partner, which enables the subsequent use of visual gestures to convey the meaning or content of the message. For example, Tomasello et al. (1994) noted that the chimpanzees in their study often used a tactile or audible attention getter (GROUND SLAP, POKE-AT, THROW STUFF) to initiate play. One chimpanzee in particular would combine a potentially tactile action (THROW STUFF) with a visual one (POUT FACE, a request for nursing), thereby bringing attention to the facial expression. However, Liebal et al. (2004), studying the same chimpanzees, failed to find reliable evidence that apes used attention-getting gestures to begin sequences. Instead, more often, subjects elected simply to move in front of another chimpanzee whose attention it wanted. And in a study of captive lowland gorillas as the San Francisco Zoo, Tanner (2004) found that less than $10 \%$ of sequences began with audible gestures; rather, extended visual communication tended to occur when the visual channel was already engaged.

Thus, there is considerable evidence to support the general hypothesis that apes use gesture sequences in different ways to increase communicative success. Sequences can be multimodal in ways that suit the communicative situation, combining tactile, visual and auditory gestures as well as facial expression and body posture. However, recent large-scale studies of gesture sequences have failed to confirm that repetition is a useful technique, and that the partner's attentional state affected gesture choice. Hobaiter and Byrne (2011) studied 81 wild chimpanzees of varied age and sex at Budongo in Uganda. Of the 4397 gestures recorded, approximately $40 \%$ were part of 723 sequences containing up to 11 gestures (using a 1-s maximum time interval between gestures). Repetitions of a gesture - which accounted for $15 \%$ of sequences - were no more successful at eliciting a satisfying response from a partner than the same gesture used alone. More generally, sequences were not more successful than the same gestures used singly, and they did not appear to function as more emphatic alternatives to single gestures. There was also no sign that the chimpanzees strategically combined gestures from different modalities to suit their partner's attentional state. However, one interesting pattern was noted. With increasing age, the chimpanzees used sequences and bouts less frequently, but at the same time, they became more successful at gaining a satisfying response from their partner using few gestures. These findings led Hobaiter and Byrne to propose a Repertoire Tuning Hypothesis: through the use of varied gestures in sequences, maturing chimpanzees learn to select the most effective gestures to use individually.

An extensive study of Western lowland gorillas also failed to find evidence that gesture sequences improved communication success. Genty and Byrne (2010) studied a wild population of approximately 130 gorillas and also 30 gorillas of varied age and sex from three different zoos. Using a 1-s maximum inter-gesture interval, 1605 sequences were observed. The sequences varied from 2 to 8 gestures in length, but they often included repetitions of the same gesture, and about two-thirds of sequences consisted of just two gestures. Overall, the sequences did not show evidence that they were produced with persistence towards a communicative "goal," i.e., a response that satisfied the gesturer enough to stop his or her gesturing. As Genty and Byrne define it: "We treated the reaction of a recipient that apparently satisfied the signaler as the gesture's goal, i.e. if that reaction was obtained, the signaler would stop, but if it was not the signaler would persist" (p. 4). They found that neither same-gesture nor mixed gesture sequences were more effective than a single gesture in reaching a goal, and the use of sequences was seldom in reaction to the communicative failure of an initial gesture. Longer sequences of repeated gestures also did not increase the likelihood of a response.

These results led Genty and Byrne (2010) to determine that there was no clear reason that gorillas elected to use sequences rather than single gestures. Thus their operating notion of communication success and failure appeared to be a dead end in the search to explain the function of gesture sequences. However, Genty and Byrne offer an alternative. They note that sequences of gestures were especially common in play contexts, and they suggest that gesturing in sequences may be a means of play regulation. As they put it, "The gorilla making a sequence of gestures-and more than one individual may be doing so-is continuously modulating the behaviour of the play partner, variously encouraging, damping down or switching the nature and tempo of interaction, responding continuously to the partner's actions ... Thus, for the playing gorilla, the "aim" of signaling may be seen as keeping the game going with some enthusiasm, while nevertheless damping down interaction that is becoming too violent or rough" (pp. 14-15). In proposing this idea, Genty and Byrne quote Barbara J. King's (2004) aptly 
named book The Dynamic Dance: "Information is neither transferred by facial expressions, body movements, gestures and vocalizations, nor by bits of information that they supposedly carry. These movements (of the face, body, limbs or vocal tract) become communicative when the social partners enter into an interaction. The social partners ... may transform each other as they act" (p. 52). In this way, Genty and Byrne suggest that gorillas might produce gesture sequences to exercise continual adjustment of the tempo and nature of social interactions, rather than conveying semantically referential information or syntactic structures.

However, perhaps because of the quantitative nature of their analyses, Genty and Byrne (2010) do not provide any specific examples of how this might happen. Indeed, the dynamic nature of ape gesturing poses a critical methodological challenge for ape gesture studies. According to this idea, the "meanings" of the gestures - the mutual understanding that is achieved emerge through interaction (Fröhlich et al., 2016a, 2016b; King, 2004). And yet, most ape gesture studies adopt operations like formal coding schemes (e.g. ethograms), inferred 'goal'-based criteria of successful communication, and categorical definitions of 'gesture', which systematically lead researchers to gloss over considerable detail that is crucial to understanding how gestures function meaningfully within an interaction. ${ }^{2}$

In contrast to this traditional approach, Tanner (2004) presents a more qualitative, interaction-based analysis of gesture sequences produced by gorillas at the San Francisco Zoo. The subjects of Tanner's study - an adult (silverback) male Kubie and an adult female Zura - often interacted in play, but typically had different ideas about how to move and position each other and of the type of play that was desired. For example, in one particular instance, Kubie attempts to move Zura into his lap, similar to some previous interactions between them, but she is hesitant (see Example 1). Over the course of the interaction, Kubie reshapes his communication according to Zura's reactions, as decisions of when, where and how to play evolve gradually through their gesturing, posturing, facial expressions and other tactile communication. Notably, despite the rich gestural communication that takes place in this interaction, it would typically be labeled as "unsuccessful" because Zura ultimately terminated the session by leaving the scene. Overall, Tanner finds that the gorillas produced sequences of gestures to serve various functions: gaining the partner's attention, directing movement and location, and cutting off the interaction. The use of some gesture types, deemed "negatives," was associated with reduced contact between the gorillas. Tanner's qualitative analysis also captures several "exchanges" between Kubie and Zura, in which they produced alternating and overlapping gestures with each other.

In summary, studies of ape gesture sequences reveal mixed findings concerning their function, without any clear conclusions. Gesture combinations may reflect emotional arousal; they may be used persistently to achieve a goal, or to elaborate when a partner fails to understand; they may contain an initial attention-getting component; they may be a means to determine the most successful single gestures; or they may serve in the dynamic regulation of playful or sexual interactions. In the next section, we propose that one reason for the somewhat incoherent mix of results is that there are actually (at least) two distinctive types of gesture sequences, each with a qualitatively different sort of function. One of these types, in particular, has been neglected by ape gesture studies: gesture sequences for display.

\subsection{Gesture sequences for display}

In their study of Western lowland gorillas, Genty and Byrne (2010, p. 292) used Markov transition analysis to discover two clusters of gestures that were frequently used in combinations with each other. Although analysis did not find any clear functional difference between them, the two clusters are quite distinct from each other. As shown in Fig. 1, Cluster 1 emerges as a group of silent tactile gestures used at close range, often in the context of play invitation or modification. Gestures in this cluster, in order of descending frequency, are One-handed Grab, Touch, Two-handed Grab, Grab-pull, Bite, and Pounce. Notably, many of these gestures belong to the type Tanner and colleagues consider iconic (Perlman et al., 2012, 2014; Tanner, 2004; Tanner and Byrne, 1996; also see McNeill, 2012, p. 72). Such gestures attempt to direct another's movement by pushing, pulling, nudging, tugging, etc., typically (but not necessarily) with mechanically ineffective force (see Footnote 2). The iconicity of these gestures relates to the direction and implied force of the gesture, which reflect the particular movement desired of the partner.

In contrast to the silent, tactile gestures of Cluster 1, Fig. 1 shows that Cluster 2 consists largely of audible gestures, with only one of them, SLAP OTHER, making tactile contact with the partner. This group includes (in descending order of frequency of use), CHEST BEAT, SLAP OTHER, DRUM OBJECT, STOMP, PUNCH OBJECT, ARM SWING, SLAP OBJECT, BOW, and JUMP. The most common starting gestures for Cluster 2 sequences were CHEST BEAT, DRUM OBJECT Or PUNCH OBJECT, which may have served to gain the attention of a potential partner from a distance. Not mentioned by Genty and Byrne is the striking similarity of many of the elements in Cluster 2 to components of the mountain gorilla chest beating display studied in the classic work of George Schaller (1963/1976). In particular, several of the percussive gestures in Cluster 2, such as CHEST BEAT, SLAP OTHER, SLAP OBJECT, and STOMP, resemble elements of the display described by Schaller - CHEST BEATING, SLAPPING, and GROUND THUMPING.

\footnotetext{
${ }^{2}$ A notable example is the standard definition of gestures as "mechanically ineffective," which systematically discards any tactile communication that physically moves the partner. This imposes binary distinctions between gesture and action, which can be tricky with tactile gestures like a pusH or PuLl. For instance, Perlman et al. (2012) observed that apes produce directive tactile gestures with variability in the degree of physical force, from gentle taps to highly forceful dragging or pushing, depending on the needs or desires of the interacting partner. Another shortcoming of the "mechanically ineffective" criterion is that it does not apply well to audible actions like DRUMMING, BEATING or SLAPPING on the self or external objects. These are commonly considered gestures, but require mechanically effective movements for sound making.
} 

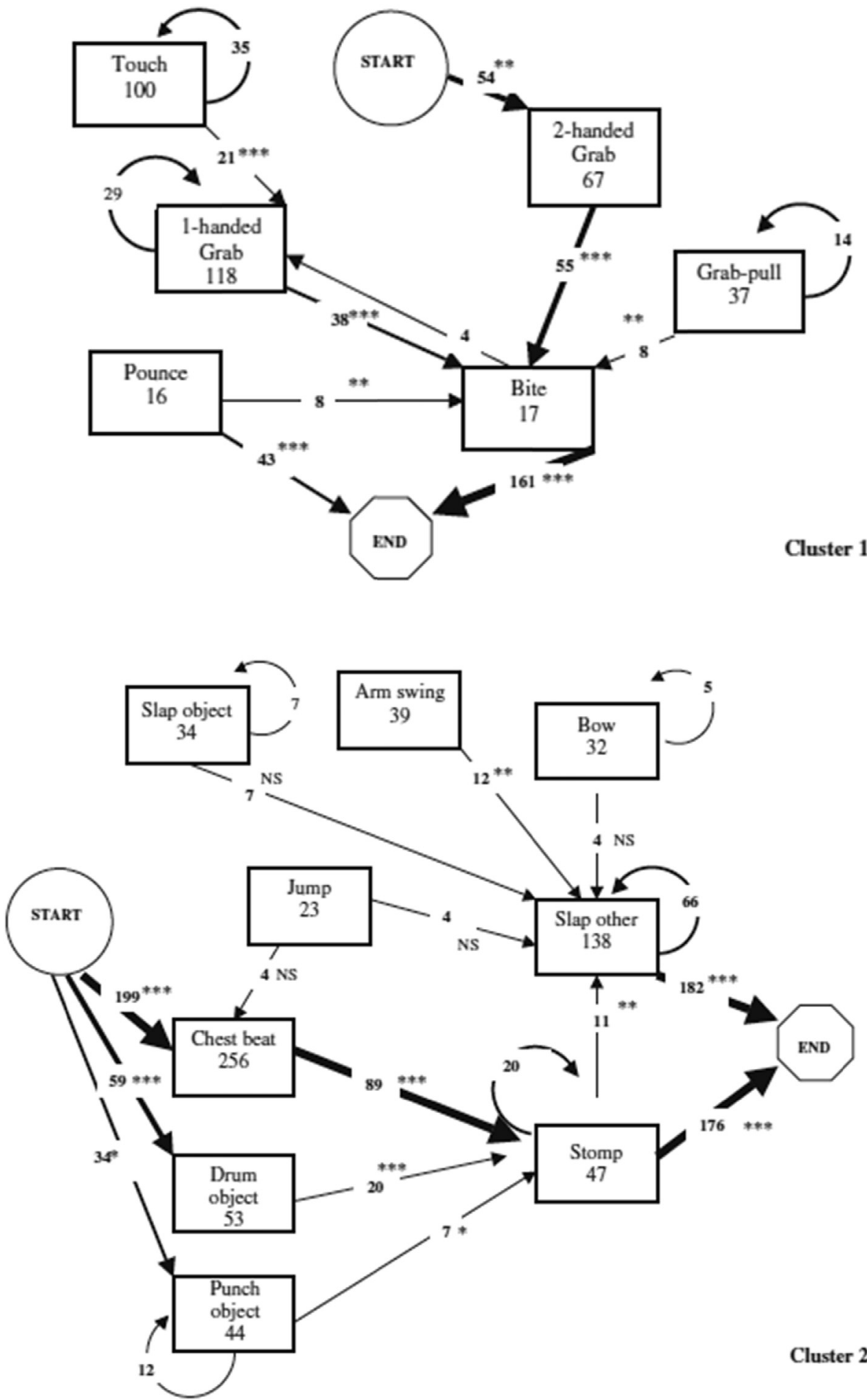

Fig. 1. From Genty and Byrne (2010), p. 7. The top Cluster 1 contains tactile gestures typically used to direct another's movement and positioning. The bottom Cluster 2 contains predominantly audible gestures typical of display, particularly the chest beating display.

In animal behavior, the term display refers to evolutionarily derived behaviors used by an animal to signal information to others, often in courtship or agonistic interactions (Tinbergen, 1952). Displays can serve to indicate the physical fitness of an animal to a potential rival or mate, and they can provide a means for animals to avoid actual fighting that might be harmful to both parties. The African apes, in particular, are notable in their performance of percussive displays (Fitch, 2012), as in, for example, tree drumming by chimpanzees (Goodall, 1986), and most prominently, the chest beating display of gorillas 
(Schaller, 1963/1976). In his research on mountain gorillas in the Virunga Mountains, Schaller spent $466 \mathrm{~h}$ in direct observation of gorillas and recorded roughly 3000 observations of chest beating. He found that chest beating was a salient element in a prototypical display series that consisted, in its complete performance by mature (silverback) males, of 9 main elements: HOOTING, SYMBOLIC FEEDING (leaf between lips), RISING, THROWING, CHEST BEATING, LEG KICKING, RUNNING, SLAPPING AND TEARING VEGETATION, and GROUND THUMPING WITH PALM OF HAND. According to his observations, CHEST BEATING and the other elements of the display series were precipitated by the presence of humans, another gorilla group or lone male, an undetermined disturbance, or by the display of another member of the group.

Schaller speculated that display sequences are a displacement activity used to release tension during emotionally arousing situations (1963/1976). However, he also observed considerable flexibility and versatility in the displays. Although "there was a definite tendency for some [elements] to precede others and for several to be united in a series" (p. 222), the sequences were not usually performed to completion with all 9 elements. The elements could occur in different orders, and they could be performed alone as single gestures. Although performance by mature males was most common, various portions of the display were performed by individuals of different ages and sexes. Infants attempted chest beating from 4 months; females used the same display elements but in shorter series and less intensely, and there was individual variability in form at all ages. ${ }^{3}$ For infants and juveniles, displays typically occurred in the context of play. Thus, in contrast to the highly stereotyped displays that are typical across animals (Morris, 1957), the chest beating display of gorillas appears to be quite flexible.

Genty and Byrne (2010) failed to find evidence that the gesture sequences in Cluster 2 were performed to achieve any particular communicative "goal." However, from the perspective of display, the function of these activities would not be to communicate a specific message, or to elicit a particular response from a partner. Instead, they may be better understood as exhibitions of energy and fitness. Schaller's (1963/1976) seminal report documented some of the remarkable versatility that gorillas exhibit in their chest beating and percussive displays. Our own observations of captive gorillas suggest that the potential for versatility in these displays is remarkable, indeed. In the next section, we illustrate this with detailed description and analysis of five examples found in our video records of gorillas at the San Francisco Zoo.

\section{Examples from San Francisco Zoo gorillas}

Our examples come from video of the San Francisco Zoo gorillas from 1989 to 1994, recorded by the first author and her husband, Charles Ernest, during their weekly observations of this group. Over the time span of the recordings, the small troop of gorillas lived together in an indoor/outdoor enclosure of 2300 square meters. The troop included two mature males, three mature females, and a male infant; another male infant was present by the time the last example was videotaped.

The main purpose of our examples is to illustrate some intriguing qualities we have observed in the percussive display sequences of gorillas, particularly the potential for hierarchical organization, innovation, and interactivity. For each example, we give a brief introduction to its context and then provide description and analysis of the action (or sometimes interaction). The first example, as a point of contrast, shows sequences of gestures that were used by Kubie, a young adult male, to negotiate positioning with Zura, a young adult female - similar to the gestures of Genty and Byrne's (2010) Cluster 1 (see Fig. 1). The other four examples are of display-like sequences. Two are of "duo" interactive displays performed by Kubie - with Zura in the first example, and with an older adult female, Bawang, in the second. The other two examples are of solo performances by individual gorillas. The first solo - a playful display performed on multiple occasions by Kubie - appears to be his unique invention. The second solo, performed by the juvenile male Shango, consisted of a sort of repeated "game", which also seems to be an individual invention.

\subsection{Example 1: Kubie and Zura negotiate positioning}

Our first example is an interaction that took place on July 10,1989, between the male Kubie, who was 13 years old at the time, and female Zura, who was 8 years old. On several occasions earlier that day, Kubie had attempted to get Zura to position herself in his lap for sexual play. In this particular interaction, as seen in Video 1 (mperlman.org/Sequences/Video 1_Kubie\&Zura.mov), ${ }^{4}$ the two gorillas sit next to each other in the grass on a pile of burlap bags. Their legs are touching, and they face each other at an angle so they can easily make eye contact. Table 2 shows the sequence of gestures and actions that occurred over the course of about a minute. At first, Kubie performs gentle tactile gestures, indicating to Zura the direction to turn her body - presumably, around, so that her rear faces his frontal area. Zura remains passively resistant, and Kubie's gestures become more forceful. Zura eventually runs away from the location. By common technical criteria (cf. Hobaiter and Byrne, 2014), this sequence of gestures was ultimately not successful for Kubie's putative goal of maneuvering Zura into a potential mating position. For Zura, however, the outcome she chose - cutting off contact when Kubie became too forward - was apparently satisfactory.

Supplementary video related to this article can be found at http://dx.doi.org/10.1016/j.langcom.2016.10.006.

During the interaction, the gorillas perform a multitude of visible and especially tactile gestures, manipulatory actions, facial expressions, and postural and locomotive movements. These gestures could be delineated into sequences and bouts

\footnotetext{
3 Tanner and Byrne (1999) observed that chest beating is not comfortable for lactating females.

4 The sound in Video 1 has been removed because of distracting noise from zoo visitors.
} 
according to the time interval between gestures. However, in practice, they occur with little distinct pause, and when gestures are on hold, the pauses are still filled with facial expression and eye contact. Many of the gestures performed by the gorillas resemble the sorts of tactile, play-regulatory gestures identified in Genty and Byrne's (2010) Cluster 1. The gestures are for the most part silent. They also appear to be iconic: for example, Kubie's lightly tapping or pulling Zura's body part, or brushing his arm across her body in a certain direction. Zura also performs iconic gestures to direct Kubie: knocking his hand away or pushing his hand back into his lap. In these instances, the direction and implied force of the gestures reflect the particular movement desired of the partner. The distinction between gesture and manipulatory action is fuzzy (cf. Perlman et al., 2012).

In contrast to this tactile, mostly silent interaction between Kubie and Zura, the next two examples are of a very different sort of gesturing. The sequences of gestures described in Examples 2 and 3 are rich in percussive sound and exhibit many characteristics of classic gorilla display described by Schaller (1963/1976), and seen in Genty and Byrne's (2010) Cluster 2.

\subsection{Example 2: Kubie and Zura perform a long-range duo display}

This example is a duo display performed by Kubie, a 13-year-old adult male, and Zura, an 8-year-old young adult female. It took place a week after Example 1, on July 17,1989. A prominent element in the display was a nest that Kubie had constructed from burlap bags provided to the gorillas as enrichment. The nest was located in open grass about $2 \mathrm{~m}$ from the base of a rock structure approximately $4 \mathrm{~m}$ high and $8 \mathrm{~m}$ on a side. Zura used this rock "hill" as her retreat, often climbing to the top of it. Although earlier in the day, in this same location, Kubie and Zura had engaged in chasing, wrestling and trading places, in the example here, they maintained roughly a ten-meter distance between each other.

As seen in Video 2, the interaction continued for over $12 \mathrm{~min}$ as Kubie and Zura exchange various bouts of gesture and percussive sound making (mperlman.org/Sequences/Video 2_Kubie\&Zura.mov). Table 3 shows the sequences of gestures and other actions that comprised the bouts (from $1 \mathrm{~min} 19 \mathrm{~s}$ through $6 \mathrm{~min} 5 \mathrm{~s}$ in the video). Throughout the display, Kubie remains near his nest performing varied combinations of gestures including CHEST BEATING, HEAD SHAKING, CLAPPING, and TWIRING his body. Zura joins in while remaining on the rock structure, punctuating Kubie's displays with her own percussive actions: BEATING her chest or SLAPING other body areas, and using the artificial rocks to produce extra sound effects by FOoT STAMPING. Zura's bouts thus alternate and sometimes overlap with Kubie's gestures. Over the course of the interaction, the gorillas appear to seek each other's visual attention, though the video quality obscures precise eye direction. The session ends as Zura leaves the area, although she eventually returns and a chase onto the rocks ensues.

Supplementary video related to this article can be found at http://dx.doi.org/10.1016/j.langcom.2016.10.006.

Table 2

Transcription of Kubie and Zura's tactile gesture sequences in Example 1.

\begin{tabular}{|c|c|c|}
\hline Time & Gorilla & Gesture and actions \\
\hline 0.06 & Kubie & SHAKES HEAD sideways $(6 \times)$ with strong motion toward himself \\
\hline 0.13 & Zura & Bends over and leans into Kubie, quickly sits up again \\
\hline 0.17 & Kubie & Motions down $(3 \times)$ on Zura's back with one arm, then with both arms \\
\hline 0.18 & Kubie & HEAD NODS $(4 \times)$ downward \\
\hline 0.23 & Kubie & HEAD TURNS $(4 \times)$ from side to side \\
\hline 0.25 & Zura & Thrusts elbow, oPENS MOUTH WITH TEETH, makes EXTENDED LIP POUT, looks Kubie in eyes, action pauses \\
\hline 0.31 & Zura & Turns face from Kubie \\
\hline 0.31 & Kubie & TAPS Zura's knee $(19 \times)$ agitatedly \\
\hline 0.38 & Kubie & Pulls hand around Zura's arm and knee, toward himself \\
\hline 0.39 & Kubie & HEAD TURN, thrusts elbows up as Zura turns toward him \\
\hline 0.39 & Zura & Moves arm out toward Kubie, KNOCKING his hand AWAY, PUSHES his hand back into his lap \\
\hline 0.42 & Kubie & PusHes Zura's side at her waist \\
\hline 0.47 & Zura & TAKES Kubie's HAND with both her hands and places it into his lap \\
\hline 0.48 & Kubie & PUSHES Zura's shoulder \\
\hline 0.51 & Kubie & PusHEs Zura's elbow \\
\hline 0.52 & Kubie & PusHes Zura's waist \\
\hline 0.55 & Kubie & Pulls hand around Zura's waist toward himself \\
\hline 0.59 & Kubie & HEAD NODS $(4 \times)$ very forcefully \\
\hline 1.01 & Kubie & Moves arm Down $(2 \times)$ Zura's back with open palm, quickly and forcefully \\
\hline 1.03 & Kubie & HEAD TURN, moves arm down Zura's back more gently \\
\hline 1.05 & Zura & AwAY motion with elbow, rises and runs away \\
\hline
\end{tabular}

Note: Small caps indicate primarily visible gestures and facial expressions. Italics indicate tactile gestures and actions. Other actions and details in regular font.

As shown in Table 3, Kubie initiates the exchange with an impressive bout of five sequences. The initial sequence contains four main elements: SHAKE HEAD with CHEST BEAT, then TOSS BAG OVER SHOULDER, and finally CLAP. Each subsequent sequence in the bout makes use of these four elements in the same order, but builds on them by inserting various new elements. The extended fifth sequence ends with the SHAKE HEAD gesture that previously had initiated all of the sequences. A second bout by Kubie was abbreviated compared to the first, but still incorporated several gestures from the first: SHAKE HEAD, CHEST BEAT, WRING BAG, TWIRL BODY and also a penultimate CLAP. Table 3 displays these recurring patterns and their alterations in schematic notation. 
Over the course of the session, Kubie and Zura each perform extended bouts of display in alternation and sometimes overlapping with each other as they join together in percussive sound making. For example, during the final part of Zura's first bout, Kubie joins in the CHEST BEATING, starting slowly, and then accelerating. And during Zura's final bout culminating with a long series of 18 CLAPS, Kubie joins with a synchronous CHEST BEAT as he lies on his back in his nest with the bag stretched from mouth to feet. Human visitors even join in the percussive display, providing a spontaneous outburst of clapping at the end of this sequence when Kubie Bows down (as well as at the end of other bouts).

Notably, Kubie keeps the burlap bag in his mouth throughout the entire display, and in fact, before each cLAP, he takes the time to toss the bag over his shoulder so that it is not in the way. This innovative oral element of Kubie's display may relate to Schaller's (1963/1976) observations of symbolic feeding and throwing and tearing of vegetation in the chest beating displays of wild mountain gorillas.

Table 3

Transcription and schematic representation of Kubie and Zura's duo display in Example 2.

\begin{tabular}{|c|c|c|c|c|c|}
\hline Time in video & Gorilla & Bout & Seq. & Gestures and actions & Structure \\
\hline $1 \mathrm{~min} 19 \mathrm{~s}$ & Kubie & 1 & 1 & $\begin{array}{l}\text { Seated, bag in mouth, (A) SHAKE HEAD + (B) CHEST BEAT, (C) TOSS BAG OVER } \\
\text { SHOULDER, (D) CLAP }\end{array}$ & $\mathrm{AB} C \mathrm{D}$ \\
\hline $1 \mathrm{~min} 26 \mathrm{~s}$ & Kubie & 1 & 2 & $\begin{array}{l}\text { SHAKE HEAD + CHEST BEAT, (E) NOD HEAD + (F) WRING BAG, TOSS BAG OVER SHOULDER, } \\
\text { CLAP }\end{array}$ & AB EF C D \\
\hline $1 \min 36 \mathrm{~s}$ & Kubie & 1 & 3 & SHAKE HEAD + CHEST BEAT, NOD HEAD, TOSS BAG OVER SHOULDER, CLAP & $A B E C D$ \\
\hline $1 \mathrm{~min} 50 \mathrm{~s}$ & Kubie & 1 & 4 & $\begin{array}{l}\text { SHAKE HEAD }+ \text { CHEST BEAT, SHAKE HEAD }+(G) \text { POUND GROUND, }(H) \text { FOLD ARMS, TOSS BAG } \\
\text { OVER SHOULDER, CLAP }\end{array}$ & AB AG H C D \\
\hline $2 \min 09 \mathrm{~s}$ & Kubie & 1 & 5 & $\begin{array}{l}\text { SHAKE HEAD + CHEST BEAT, stands bipedally, stands quadrupedally, (I) TWIRL } \\
\text { WHOLE BODY, stands bipedally, TOSS BAG OVER SHOULDER, CHEST BEAT, bows down, } \\
\text { SHAKE HEAD, lies down, rolls into nest }\end{array}$ & AB I C B A \\
\hline $2 \min 52 \mathrm{~s}$ & Zura & 1 & 1 & On high rocks, $(J)$ sтAMP FоOT $(3 \times)$, pauses & $\mathrm{J}$ \\
\hline $3 \min 05 \mathrm{~s}$ & Zura & 1 & 2 & CHEST BEAT, STAMP FOOT $(2 \times)$, moves down on rocks & B J \\
\hline $3 \mathrm{~min} 10 \mathrm{~s}$ & Zura & 1 & 3 & (K) SLAP ROCK $(4 \times)$, CHEST BEAT, $(\mathrm{L})$ PAT SHOULDERS WITH CROSSED ARMS, CHEST BEAT & K B L B \\
\hline $3 \min 26 s$ & Kubie & 2 & & Lying in nest, CHEST BEAT & B \\
\hline $3 \min 37 \mathrm{~s}$ & Kubie & 2 & & Sits up, CHEST BEAT & B \\
\hline $3 \min 41 \mathrm{~s}$ & Zura & 1 & 3 & CHEST BEAT, CHEST BEAT & B B \\
\hline $3 \min 48 s$ & Kubie & 2 & 1 & $\begin{array}{l}\text { SHAKE HEAD, CHEST BEAT, stands bipedally, TWIRL BODY }(2 \times) \text {, CLAP, bows, WRING BAG, } \\
\text { CLAP, WRING BAG, lies down }\end{array}$ & A B I D F D F \\
\hline $4 \min 19 \mathrm{~s}$ & Zura & 2 & 1 & SтAмP ғоот $(2 \times)$, moves down rocks, lies down, sits up & $\mathrm{J}$ \\
\hline $4 \min 36 \mathrm{~s}$ & Zura & 2 & 2 & (M) ARM SHAKE, CHEST BEAT, CHEST BEAT, turns to Kubie, WRING ARMS & M B B F \\
\hline $4 \min 40 \mathrm{~s}$ & Kubie & 3 & 1 & $\begin{array}{l}\text { CHEST BEAT, sits up, CHEST BEAT, stands bipedally, TWIRL BODY, CHEST BEAT, TWIRL } \\
\text { BODY, CHEST BEAT moves quadrupedally to sit in nest, then writhes around in } \\
\text { nest as Zura continues to gesture }\end{array}$ & B B I B I B \\
\hline $4 \min 50 \mathrm{~s}$ & Zura & 2 & & ChEST BEAT & B \\
\hline $5 \min 15 \mathrm{~s}$ & Zura & 2 & 3 & SHAKE HEAD $+(0)$ POUND LAP & $\mathrm{AO}$ \\
\hline $5 \min 29 \mathrm{~s}$ & Zura & 2 & & Chest BEAT & B \\
\hline $5 \min 43 \mathrm{~s}$ & Zura & 3 & 4 & POUND LAP, CLAP $(\mathbf{1 8} \times)$ & O D \\
\hline $5 \min 48 \mathrm{~s}$ & Kubie & & & Chest BEAT & B \\
\hline $6 \mathrm{~min} 05 \mathrm{~s}$ & Zura & 2 & & POUND LAP & 0 \\
\hline
\end{tabular}

Note: Small caps indicate gestures. Italics indicate positional, locomotory or postural elements. + indicates elements performed simultaneously by a single gorilla. Bold indicates elements performed simultaneously by both gorillas. A blank sequence number reflects that only a single gesture was produced. Structure is represented using the alphabet according to order of appearance of the gestures.

\subsection{Example 3: Kubie and Bawang perform a close-range duo display}

This example was part of a longer play session (approximately $20 \mathrm{~min}$ ) between Kubie, here aged 14 years, and Bawang, a female aged 9 years. This took place on June 24, 1990 (see Video 3: mperlman.org/Sequences/Video 3_Kubie\&Bawang.mov). Bawang had previously mated with Kubie, resulting in a male offspring, Shango, who was now 1 year, 4 months of age - old enough to be somewhat independent. In this scene, Kubie and Bawang sat close together within an artificial rock 'cave' that gave them some privacy from observers.

Supplementary video related to this article can be found at http://dx.doi.org/10.1016/j.langcom.2016.10.006.

Ten to fifteen minutes prior to the interaction we focus on here, Kubie had taken a burlap bag (see Example 2) into the rock cave and lain down. Throughout the ensuing action between the gorillas, the bag served as a mutual center of attention and exchange. (See Tanner and Byrne (2010) where this episode is featured as an example of triadic play with mutual attention to an object.) Bawang was nearby, and to solicit Kubie's attention, she gestured to him with HEAD TWIRIS, BRANCH TOSSING, CHEST BEATING, HEAD TOSSING and SLAPPING on the rocks. Kubie stayed prone while Bawang sat nearby tossing and catching some leaves. This is the point where our Video 3 begins. Both gorillas get up and begin to interact. Bawang takes Kubie's bag, and at 0 min 59 s, puts it over her head, and cHEST BEATs beneath it. They tussle a little, and Kubie takes back the bag. At 1 min $44 \mathrm{~s}$, Kubie puts the bag over Bawang's head. He pats her with the bag, and she sтомасн BEATS. At 3 min 02 s, Bawang PLAY BITES Kubie's neck, and the exchange in Table 4 followed. 
Table 4

Transcription of Kubie and Bawang's duo display in Example 3.

\begin{tabular}{|c|c|c|c|}
\hline Time in video & Gorilla & Joint bout number & Gestures and context \\
\hline $3 \mathrm{~min} 11 \mathrm{~s}$ & Bawang & 1 & Both gorillas seated, BODY вEAT on stomach \\
\hline $3 \mathrm{~min} 14 \mathrm{~s}$ & Kubie & 1 & Puts bag over head, ВОDY ВЕАТ on chest \\
\hline $3 \mathrm{~min} 15 \mathrm{~s}$ & Bawang & 1 & CLAP both hands and feet \\
\hline $3 \mathrm{~min} 18 \mathrm{~s}$ & Kubie & 1 & Hгт Bawang's face with bag, puts bag over her head \\
\hline $3 \mathrm{~min} 30 \mathrm{~s}$ PAUSE & & & Gorillas engage in wrestling under the bag \\
\hline $3 \min 38 \mathrm{~s}$ & Bawang & 2 & Bawang bites bag, pulls it in mouth like tug, BODY BEATS \\
\hline $3 \mathrm{~min} 40 \mathrm{~s}$ & Kubie & 2 & BACKHAND HIT on Bawang's face \\
\hline $3 \min 45 \mathrm{~s}$ & Kubie & 2 & HEAD NOD \\
\hline $3 \mathrm{~min} 49 \mathrm{~s}$ & Kubie & 2 & BODY BEAT, HEAD TWIRL with bag in mouth \\
\hline $3 \min 49 \mathrm{~s}$ & Bawang & 2 & BODY BEAT, CLAP FEET \\
\hline $3 \min 56 s$ & Kubie & 2 & BACKHAND HIT gently on Bawang's face \\
\hline \multicolumn{4}{|c|}{3 min 58 s PAUSE, camera cut } \\
\hline $4 \min 17 \mathrm{~s}$ & Bawang & 3 & $C_{\text {LAPS }}$ hand to fist and feet, CHEST BEAT \\
\hline $4 \mathrm{~min} 17 \mathrm{~s}$ & Kubie & 3 & Kubie has bag in mouth \\
\hline $4 \mathrm{~min} 30 \mathrm{~s}$ PAUSE & & & Gorillas engage in gentle wrestling \\
\hline $4 \min 52 \mathrm{~s}$ & Bawang & 4 & Puts bag in mouth, HEAD SHAKE AND TWIRL, BODY BEAT \\
\hline \multicolumn{4}{|l|}{$4 \mathrm{~min} 58 \mathrm{~s}$ PAUSE } \\
\hline $5 \mathrm{~min} 06 \mathrm{~s}$ & Bawang & 5 & BODY BEAT, CLAPS HANDS ON FEET \\
\hline $5 \mathrm{~min} 06 \mathrm{~s}$ & Kubie & 5 & CHEST BEAT \\
\hline $5 \min 09 \mathrm{~s}$ & Kubie & 5 & LIFTS HANDS as if to hit Bawang, ONE-HAND HIT gently on Bawang \\
\hline $5 \mathrm{~min} 14 \mathrm{~s}$ PAUSE & & & \\
\hline
\end{tabular}

Note: Small caps indicate gestures. Brackets indicate positional, locomotory or postural elements. Bold indicates that the actions were performed simultaneously by Kubie and Bawang.

All of the activity presented in Table 4 occurred with the two gorillas seated in one place, face to face. Though the gorillas were close enough to use tactile iconic gestures, it does not appear that they are attempting to influence each other's position or location. Rather, many of the gestures and actions they produce appear to mirror those of their partner. Thus, the gorillas' quick, often overlapping exchanges seem to involve creative interplay between each other's gestures, with gestures like BoDY BEATING and BAG TWIRLING serving as punctuation. This session was quite different in quality from Kubie's long-range exchanges with Zura described in Example 1, and also from Kubie's close-range engagement with Zura described in the introduction. Here, Kubie and Bawang interact in a duet performance with equal participation. Although it can be sliced into 'bouts' and also into some individual sequences, the considerable portions of overlap and rapid turn-taking may be interpreted more sensibly as jointly produced activities. This quality is reflected in Table 4, which counts bouts as activity by either or both gorillas occurring without a pause of more than a second.

Several of the bouts end with Kubie reaching over and gently hitting Bawang's head with a SLAP Or BACKHAND. However, the hitting and their competition for the bag is playful and does not escalate into more serious activity or contact, though there is some gentle wrestling between bouts. There does not appear to be a 'goal' other than the continuation of interaction (cf. Genty and Byrne, 2010). Although some of the gestures used are those of display, this context is quite different from those described by Schaller (1963/1976). In this case, the gorillas seem to have constructed together a more intimate 'game,' which was especially suited to the tight space afforded by the 'rock cave'.

\subsection{Example 4: Kubie repeats a solo display with a rubber tub}

This example is of two repeated performances of a solo display by Kubie at age 18 years (see Video 4a: mperlman.org/ Sequences/Video 4a_Kubie.mov and Video 4b: mperlman.org/Sequences/Video 4b_Kubie.mov). The first instance occurred on August 8, 1993, and the second about a month later, on September 10, 1993. In the first performance, both 5-year-old Shango and adult female Zura sit watching nearby. Four seconds after Kubie completes the display, both get up and move around, turning their backs to him. In the second performance, Kubie is visible to Shango, Zura, and older male Bwana, though at a greater distance than in first performance. During the long pause before he vocalizes and jumps, Kubie repeatedly looks toward Bwana, who gets up from his seated position beside a tree and walks away as Kubie watches. As Kubie jumps, Bwana pauses, and they look at each other; Kubie walks in the opposite direction and interaction ends.

Supplementary video related to this article can be found at http://dx.doi.org/10.1016/j.langcom.2016.10.006.

As shown in Table 5, Kubie's two performances of this 9-part action sequence are nearly identical, repeating the same elements in the same order, but with some small variations. The actions, which focus around a large rubber tub, can be analyzed into nine essential components (A-I) that are shared across both performances. In the first observation of the sequence, Kubie $\left(A_{1}\right)$ moves the rubber tub from behind a tree about $5 \mathrm{~m}$ away $\left(\mathrm{B}_{1}\right)$ to a location behind a rock ledge. Then he (C) climbs onto the rock ledge and turns $\left(\mathrm{D}_{1}\right)$ the tub bottom up. He ( $\left.\mathrm{E}_{1-}\right)$ stands quadrupedally, with his legs on the rock and his arms on the ground, and then (F) stands upright and $(\mathrm{G})$ CHEST BEATS with a whinny-like vocalization. He finally (H) jumps up and off the ledge and (I) lands bipedally on the tub. In comparison, Kubie's second performance a month later varies only in a few respects. This time, he brings the tub to the rocks gradually, from a farther distance away where it sat in a drainage ditch 
$\left(A_{2}\right)$. He also reverses the order in which he climbs onto the rock ledge and positions the tub $\left(B_{2}, C\right)$, and in the second instance he throws the tub into position $\left(D_{2}\right)$. He also crouches quadrupedally on his elbows before standing $\left(E_{2}\right)$. In addition to these two performances, on the day of the second observation Kubie repeated a portion of the full sequence two more times. About an hour after the first performance, he posed quadrupedally but moved to sit on the tub without a jump, and an hour and a half later he posed quadrupedally, then jumped and roared. Because observations by researchers were made only once a week, it seems likely that he may have performed variations on this display sequence on more occasions than were observed.

Table 5

Transcription of Kubie's solo displays in Example 4.

\begin{tabular}{|c|c|c|c|c|c|}
\hline $\begin{array}{l}\text { Time in } \\
\text { video }\end{array}$ & $\begin{array}{l}\text { Element } \\
\text { order }\end{array}$ & Display 1 (Video 4a) & $\begin{array}{l}\text { Time in } \\
\text { video }\end{array}$ & $\begin{array}{l}\text { Element } \\
\text { order }\end{array}$ & Display 2 (Video 4b) \\
\hline $1: 25: 22$ & $A_{1}$ & Moves a rubber tub from behind tree & $0: 31: 28$ & $\mathrm{~A}_{2}$ & $\begin{array}{l}\text { Moves a rubber tub, gradually, from a much longer distance } \\
\text { away in drainage ditch }\end{array}$ \\
\hline $1: 25: 40$ & $\mathrm{~B}_{1}$ & To a location under a rock ledge & $0: 32: 39$ & $\mathrm{C}$ & Climbs onto the rock ledge \\
\hline $1: 25: 42$ & $\mathrm{C}$ & Climbs onto the rock ledge & $0: 32: 42$ & $\mathrm{~B}_{2}$ & $\begin{array}{l}\text { Throws tub over to same location under rock ledge as in } \\
\text { earlier scene }\end{array}$ \\
\hline $1: 25: 44$ & $\mathrm{D}$ & Turns the tub bottom up & $0: 32: 42$ & $\mathrm{D}_{2}$ & Tub lands bottom up \\
\hline $1: 25: 46$ & $\mathrm{E}_{1}$ & $\begin{array}{l}\text { Stands quadrupedally with legs on the } \\
\text { rock and arms on the ground }\end{array}$ & $\begin{array}{l}0: 32: 47 \\
0: 33: 04\end{array}$ & $\mathrm{E}_{2}$ & $\begin{array}{l}\text { Crouches quadrupedally, with elbows on the ground, and } \\
\text { then stands quadrupedally with legs on rock and arms on } \\
\text { the ground }\end{array}$ \\
\hline $1: 25: 55$ & $\mathrm{~F}$ & Stands upright & 0:33:30 & $\mathrm{F}$ & Stands upright \\
\hline $1: 25: 55$ & G & CHEST BEAT with vocalization & $0: 33: 31$ & G & CHEST BEAT with vocalization \\
\hline $1: 25: 56$ & $\mathrm{H}$ & Jumps up and off the ledge & 0:33:31 & $\mathrm{H}$ & Jumps up and off the ledge \\
\hline 1.25 .56 & I & Lands bipedally on the tub & $0: 33: 31$ & I & Lands bipedally on the tub (tub not visible) \\
\hline
\end{tabular}

Note: Time in video refers to the time displayed in the video recording.

Kubie's performances demonstrate one gorilla's innovative variations on the elements of the classic display sequence described by Schaller (1963/1976). Given the setting of the zoo, including the rock structures and especially the large rubber tub, it was an individual composition unlikely to be performed by any other gorilla. Nevertheless, the performances contain certain elements that are similar to elements of Schaller's prototypical display sequence, including a jump or "dive forward" (p. 228), Rising and CHEST BEATING. As in the prototypical sequence, as well as in other displays by Kubie, the sequences end with a percussive sound. Thus Kubie's displays interweave innate "gorilla-typical" gestures with innovative elements that are derived from the particulars of his environment. In next example, we see a similar kind of creativity in the repeated sequences of a solitary "game" performed by an adolescent male.

\subsection{Example 5: Shango performs repeated sequences in a game with a ball}

Our final example is what appeared to be a kind of "game" played by a five-year-old adolescent male, Shango (offspring of Bawang and Kubie). Basic details of the San Francisco Zoo group and the enclosure are the same as in the previous examples. On February 25, 1994, Shango was observed playing a game which he seems to have invented. It consisted of a repeated series of actions related to rolling a ball up and down the slight incline of a concrete drainage channel. At the upper end of the channel there was a rubber tub (like the one in Example 4) and a pile of branches a bit further down the channel bounded the game location. The slope between the tub and the branches was such that once started, the ball would roll on its own until the cement flattened out.

As seen in Video 5 (mperlman.org/Sequences/Video 5_Shango.mov) Shango repeats the sequence of actions at least six times (further play with the ball can be heard, although the camera moved to a different subject). Each time, he repeats the actions in essentially the same order, but with some variations and omissions. Table 5 shows a schematic representation of the actions and variations of each sequence. In the most prototypical version (Iteration 2, Table 5) Shango, beginning at the top of the hill:

\section{A: Sets the ball in motion down hill, running bipedally and “dribbling” it.}

Once the ball is in motion, he:

\section{$\mathrm{B}_{1}$ : Lets go of it and rolls himself down the hill ahead of the ball.}

As he rolls, he:

$\mathrm{C}_{1}$ : Grabs and tosses branches, sometimes pulling them along with him. 
Then he:

$\mathrm{D}_{1}$ : Catches the ball and dribbles it back up the hill.

And finally, Shango:

$\mathrm{E}_{1}$ : Tags the rubber tub at the top.

Notably, Shango performed minor variations on these elements in different iterations of the sequence. These include variations on B, C, D, and E:

$\mathrm{B}_{2}$ : Continues to run and 'dribble' ball all the way down hill

$\mathbf{C}_{2}$ : Ball stops impeded by branches, Shango rolls self back up hill to ball then rises to set ball moving and dribbles it back up to top of hill to start over

$\mathrm{D}_{2}$ : Sets ball rolling up hill, runs ahead of it and/or rolls uphill ahead of ball

$\mathrm{E}_{2}$ : Jumps on rubber tub

$\mathrm{E}_{3}$ : Rolls through branches stopping to sit at tub

$\mathrm{E}_{4}$ : Rolls into tub

Supplementary video related to this article can be found at http://dx.doi.org/10.1016/j.langcom.2016.10.006.

Table 6

Schematic representation of Shango's game in Example 5.

\begin{tabular}{|c|c|c|c|c|c|}
\hline \multirow{2}{*}{$\frac{\text { Repetition (start time) }}{1(1: 40: 07)}$} & \multicolumn{5}{|c|}{ Sequence } \\
\hline & (A) & $\mathrm{B}_{1}$ & $\mathrm{C}_{1}$ & $\mathrm{D}_{2}$ & $\mathrm{E}_{1}$ \\
\hline $2(1: 40: 19)$ & A & $\mathrm{B}_{1}$ & $\mathrm{C}_{1}$ & $\mathrm{D}_{1}$ & $\mathrm{E}_{1}$ \\
\hline $3(1: 40: 35)$ & A & $\mathrm{B}_{1}$ & $\mathrm{C}_{2}$ & $\mathrm{D}_{2}$ & $\mathrm{E}_{2}$ \\
\hline $4(1: 40: 55)$ & A & $\mathrm{B}_{1}$ & $\mathrm{C}_{1}$ & $\mathrm{D}_{1}$ & $E_{3}$ \\
\hline $5(1: 41: 42)$ & A & $\mathrm{B}_{2}$ & & $\mathrm{D}_{1}$ & $\mathrm{E}_{4}$ \\
\hline $6(1: 41: 59)$ & A & $\mathrm{B}_{2}$ & & $\mathrm{D}_{1}$ & \\
\hline
\end{tabular}

Note. Letters denote actions as described in the text. Parentheses indicate that the element occurred just before the video cut in and not directly visible.

Unlike the previous examples of sequences, Shango's game is not composed of any distinct gestures. However, it bears some similarities to the previous displays. One correspondence is found in the way Shango tags the rubber tub as the final element $\mathrm{E}$ in the sequence. Likewise, Kubie jumps onto the tub to end his sequence in the previous example, and in Example 2 , his sequences tended to end with a percussive CLAP. Shango's game is also similar to Kubie's displays in its hierarchical structure - it is a repeating sequence of component actions that vary over iterations.

As Shango's game is solitary and does not involve communicative gestures, it is clear that his action sequences are not intended to achieve any particular social goal. Rather, in creating the game, the young gorilla seems to have given himself an individual goal of challenging his athletic skills with the ball, his favorite toy. Like Kubie's unique display in Example 3 , Shango's inventive game derives from the unique affordances of the zoo enclosure (e.g. the drainage channel) and the enrichment items provided to the gorillas (e.g. ball, rubber tub).

\section{Discussion}

Humans are masterful in their ability to communicate by arranging elements -words, signs, musical notes - into complex sequences. Thus, researchers of language evolution have taken note that other species of great apes also, rather commonly and universally, produce gestures and combine them into sequences (Genty and Byrne, 2010; Hobaiter and Byrne, 2011; Liebal et al., 2004; Tempelmann and Liebal, 2012; Tanner, 2004; Tomasello et al., 1994). However, one consistent conclusion of this research is that the sequences of apes do not show much in the way of compositional semantics, and therefore, do not appear to convey anything like linguistic "meaning." So why do great apes combine gestures into sequences?

Previous studies have found evidence pointing to several different reasons: for example, emotional arousal (Tempelmann and Liebal, 2012), persistence or elaboration towards a communicative goal (e.g. Leavens et al., 2005; Liebal et al., 2004), or perhaps a more dynamic function in regulating play (Genty and Byrne, 2010). An intriguing finding comes from a comprehensive study of gorillas, in which cluster analysis revealed two main networks of gesture sequences (Genty and Byrne, 2010). Neither of the clusters was found to serve any reliable function. Cluster 1 consisted largely of tactile, silent gestures, which may have been used to regulate play, or in our observations, for directing movement and positioning with a partner. In contrast, Cluster 2 contained a large number of percussive gestures, several of which, we observed, overlap with elements of the classic gorilla chest-beating display originally described by Schaller (1963/1976). 
In our studies of the lowland gorillas at the San Francisco Zoo, we have noticed that they produce comparable percussive sequences, particularly in playful displays and highly interactive gestural exchanges. In a few cases, their performances were quite remarkable, and worth noting in detail. To this end, we presented detailed, qualitative analysis of five of the more impressive video-recorded examples from our records. Notably, the frequently percussive sequences of our Examples 2-5 contrast markedly with the tactile (Cluster 1-like) sequences of Example 1. In the latter case, Kubie appeared to have a distinct goal: to get Zura to turn around and sit in his lap. Because Zura held some agency in this matter, Kubie used directive, iconic gestures in his attempts to persuade her to move in particular ways (and likewise, she used directive gestures to dissuade him). At times, these gestures were more forceful, to the point of being manipulatory actions.

In contrast, the sequences in Examples 2-5 may be better understood as display, rather than as communication intended to achieve an immediate goal. The function of these activities is not to communicate a specific message, or to elicit a particular response from a partner. Instead, they may be seen as multimodal performances - creative and playful exhibitions of energy and fitness. As we discuss below, from this perspective of display, the sequences of Examples 2-5 exhibit some remarkable qualities.

\subsection{Organization of display sequences}

As annotated and schematized in Tables 2-6, the displays (including Shango's game) described in our examples exhibit some interesting patterns in the ways they are organized, including both individual and "duo" performances. One of the more striking aspects of their organization is the hierarchical way in which gestures and other actions are arranged into sequences, and then repeated in larger bouts, or over multiple performances. For instance, in Example 2, Kubie repeated five iterations of an ordered sequence of four gestures (SHAKE HEAD with CHEST BEAT, TOSS BAG OVER SHOULDER, CLAP). In EXample 4, Kubie repeated his nine-part rubber-tub display sequence more than a month after his original observed performance. And in Example 5, the adolescent Shango repeated his six-part "ball game" routine at least four complete times in succession, and at least twice more performed partial versions (as recorded on video). These different forms of repetition indicate that the gorillas have both short-term and long-term memory for their sequential compositions.

What is additionally remarkable about the organization of the sequences in our examples is in their variability: the ways that some elements - gestures or actions - are modified and new elements are inserted. For example, in Example 2, each time Kubie repeated the gesture sequence, he altered it by inserting various new elements (e.g. WRING BAG, POUND GROUND), while maintaining the four-gesture skeleton. In Example 4, he adjusted some of the actions in his tub display and did so without disrupting the larger routine. For example, to position the tub under the rock ledge bottom up, in one instance he sets it in position and turns it over, and in the second instance, he throws it down from the ledge above. This kind of variability without disruption of the greater routine is also illustrated by Shango's game in Example 5. Shango improvises some modifications to the game, but still maintains certain elements (e.g. the significance of the tub upper boundary), as well as the overall flow of up-and-down movement with the ball.

Variations on a theme are typical in play activities (Loizos, 1966; Fagen, 1981; Johnson, 2010), and in a conservative interpretation these could be considered to be errors or memory failures. However, in both Shango's game as well as in Kubie's display in Example 4, the theme itself consisted of several essential actions, always in the same order (i.e. a 'program' of action), that did not change or fail regardless of other enhancements. Notably, these examples of display resemble the reorganization of routines discussed by Johnson (2010) in a paper on cognitive complexity in primates and cetaceans. As Johnson describes it: "Versatility is seen, for example, in the substitution of different acts or objects into established routines, in the size and flexibility of action repertoires that enable variably configured and sequenced performances, and in the marked occurrence of individual differences. Hierarchical organization is seen in the substitution or iteration of a subroutine that fails to disrupt its larger routine, in the simultaneous embedding of one social interaction within the frame of another and in the insertion of a novel or borrowed subroutine" (p. 1).

\subsection{Innateness and innovation in display sequences}

In many cases, the display sequences in our examples appear to reflect actions that are part of the species-typical behavioral repertoire of gorillas. The frequent use of percussive gestures and actions bears resemblance to the classic chest beating display observed by Schaller (1963/1976), and also to Genty and Byrne's Cluster 2 (Fig. 1). At least one more specific connection is evident too: a tendency for sequences to end with a percussive element. For instance, in Example 2, Kubie ended many of his sequences with CLAPS, and the final bout ended with 18 CLAPS from Kubie, as Zura joined in with synchronous CHEST BEATING - a dramatic finale. The percussive final element echoes Schaller's description of the display series of mountain gorillas, which tended to end with "a loud thump of the ground with the palm of the hand" (1963/1976, p. 222). Similarly the most frequent ending gesture of Genty and Byrne's (2010) Cluster 2 was SLAP отHER (i.e. a gorilla), followed by STOMP on the ground. SLAP OBJECT was also frequent in the cluster, sometimes leading directly to the final SLAP OTHER. In our Example 3, play bouts often ended with a HIT on the other gorilla. "SLAPPING AND TEARING VEGETATION," another kind of sLAP OBJECT, was the penultimate element of the display sequence as described by Schaller.

It is worth noting that these percussive "species-typical" displays are, to some extent, shared across species of great apes (including humans; Fitch, 2006). For one, the gorillas at the San Francisco Zoo, as well as those from the many wild and captive sites of Genty and Byrne (2010), are western lowland gorillas, a different species from the eastern mountain gorillas observed 
by Schaller, separated by an estimated 1.75 million years of evolution (Scally et al., 2012). More widely across the ape family, the male dominance and charging displays of chimpanzees include many gestures similar to those in gorilla chest beating display. Chimpanzee displays - performed mostly by males but also females - include behaviors like DRAGGING OR FLAILING BRANCHES, THROWING OBJECTS, SLAPPING GROUND, STAMPING FEET, LEAPING TO HIT AND STAMP AT A TREE (drumming display), SWAYING BRANCHES, LEAPING AND BRACHIATION IN TREE, and occasional CHEST BEATING (Goodall, 1986). Percussive display of the other ape species, bonobos and orangutans, is not so thoroughly studied.

Based on their broad sampling of wild and captive gorillas, Genty et al. (2009) concluded that gorilla gestural communication, while flexible, is composed from a species-typical repertoire of signals - comparable to the innate inventories of most other mammalian species, but much larger. Byrne (2016) further suggested that there is a lack of imagination in ape gestural communication, in that apes untaught by humans do not augment their extensive natural repertoire with new expressions. Expanding on this view, our observations point to the large range of variation found within the framework of a biologically inherited repertoire. Although the display sequences presented here show evidence of some innate proclivities, they also show great creativity in stretching and shaping the gestural repertoire. They illustrate how "gorilla-typical" displays can interweave innovative elements that are derived from the particulars of the environment. One prominent example of this is the incorporation of features of idiosyncratic objects like the burlap bags Kubie, Zura, and Bawang played with in Examples 2 and 3, the tub used by Kubie and Shango in Examples 4 and 5, and the branches and ball used by Shango in Example 5. The displays also incorporate particular features of the habitat, like the rocks Zura used to make a resonant foot stamping sound, the rock ledge Kubie jumped from, and the drainage channel used by Shango to roll his ball.

For further sense of the potential for innovation in display sequences, we additionally point out the performances of Jumbo, a 15-year-old female lowland gorilla, who resides at Limbe Wildlife Sanctuary in Cameroon, Africa. Jumbo is well known to all the caregivers there for what they call her "Jumbala Dance." Jennifer Draiss, who was a caregiver at Limbe, noted in personal communication that "anything Jumbo finds, she will make use of, either to make a new sound and incorporate it into her dance, or to make into a tool. If you give Jumbo a water bottle, she'll pull the paper wrapper off and crinkle it or put it under her arms while dancing, and she'll use the plastic for something else." An example of Jumbo performing her Jumbala Dance is shown in Video 6 (mperlman.org/Sequences/Video 6_Jumbo.mov). Jumbo shows off her personal style as she strings together long sequences of CLAPS and BODY BEATS, all the while manipulating a long branch back and forth between her foot and mouth. She conducts her performance with a characteristically calm tempo and regular spacing between gestures.

Supplementary video related to this article can be found at http://dx.doi.org/10.1016/j.langcom.2016.10.006.

As one last example of the potential for innovation in display sequences, we look to the enculturated lowland gorilla Koko (see Patterson and Linden, 1981 for background). For example, consider this sequence in which Koko gestures while wearing a pair of dark sunglasses (https://www.youtube.com/watch?v=QSaPQKqiETc; note that our interpretation is not related to the glossed "meanings" of Koko's gestures provided in the video). Koko puts on the glasses, and then, while wearing them (properly), performs a four-part sequence of gestures: she audibly TAPS the lenses with her finger tips, TOUCHES her SHOULDERS with her finger tips (forearms parallel), CHEST BEATS, and then brings her ovERLAPPING HANDs to her mouth. ${ }^{5}$ The blend of innate and innovative elements in Koko's sequence is remarkable. As is typical of gorilla displays, Koko incorporates a percussive element, but hers involves a fairly complex human artifact - sunglasses, along with the knowledge of how to wear them. Another interesting feature of the display is that her "species typical" chest beat is a silent, stylized version of the gesture. Gestures similar to Koko's version of TOUCH SHOULDERs have also been observed in the San Francisco Zoo gorillas (Tanner, 1998). OVERLAPPING HANDS may be more unique to Koko. It, along with variants like PARALLEL HANDS and oPEN HAND is often part of a more complex, "multimodal" behavior in which she brings her hands (or hand) to her mouth, and blows loudly into them, sometimes for multiple, repeated exhalations (Perlman and Clark, 2015).

It is important to point out that wild gorillas can also be innovative in the ways that they incorporate environmental affordances to stretch the innate tendency for percussive displays. An example is the 'splash display' of lowland gorillas living in swamplands of the Congo. Parnell and Buchanan-Smith (2001) observed 90 instances, with 10 variants of the display, in which the gorillas produced sounds by splashing water. As with gorillas, different chimpanzees also have their own characteristic displays that use the affordances of the environment (Goodall, 1986). Most famously, the subordinate-turned-alpha male Mike was renowned for incorporating oil cans from Goodall's camp into his special individual display.

\section{3. 'Meaning' and interactivity in display sequences}

We have made the case that some gesture sequences of gorillas are better understood as playful, multimodal displays, rather than as communication to achieve a particular goal. As displays, such sequences seem to defy traditional notions of 'meaning' assumed in many previous studies of ape gesture research. These studies typically focus on the context of use and behavioral effect of gestures on the communication partner. For example, several studies have examined the function and meaning of gestures sequences by determining whether they are 'successful' or 'unsuccessful' (Genty and Byrne, 2010; Hobaiter and Byrne, 2011; also see Roberts et al., 2013). This criterion of success is typically determined by whether the gesturer was 'satisfied' by the response of a 'recipient', the criteria being that the gesturer ceased to gesture once a 'goal' was

\footnotetext{
5 After this sequence, Koko pulls off the glasses, brings the lenses to her mouth, huffs breathily on them (see Perlman and Clark, 2015), and then makes a pantomimic gesture of wiping the glasses with a tissue, apparently to request the absent instrument (see Perlman and Gibbs, 2013).
} 
reached, as in the notion of Apparently Satisfactory Outcomes (Hobaiter and Byrne, 2014). However, in order to make their goal-based criteria coherent, Hobaiter and Byrne needed to drop play-related gestures from their analysis. As they observed, "In play, gestures are not necessarily used with their normal meaning and the outcome may not reliably signal the gesture's meaning in other contexts. In subsequent analyses, we therefore excluded data from play bouts to avoid masking the "realworld" meaning of gestures" (p. 2). By making this methodological distinction, Hobaiter and Byrne recognized a difference in the essential nature of some gesture use from other instances.

Our examples illustrate how the highly interactive, playful nature of some display sequences presents challenges to traditional approaches to gesture and meaning. As demonstrated by Kubie's duo performances with Zura and Bawang in Examples 2 and 3, display sequences can involve back-and-forth alternation, and at times, these exchanges can be simultaneous or even synchronous. Some exchanges seem to be jointly produced activities. One gorilla would begin a 'theme' with a certain gesture and the other would chime in a moment later with the same or another gesture. In these cases, the traditional roles of signaler and recipient can be unclear or interchangeable.

Such an exchange is seen in Example 2. At about $3 \min 25 \mathrm{~s}$, Zura commenced CHEST BEATING that was almost immediately joined by Kubie, and then one or the other continued for several alternations. Though physically at a distance from each other, the gorillas gazed toward each other, waiting for each other's response. Later, Zura initiated a round of CLAPPING that was joined by Kubie's CHEST BEATING. In this instance, even human zoo visitors joined in the "applause." Another example of this rich sort of alternation comes from Example 3. Kubie and Bawang established a playful routine in which bouts ended with a gentle HIT by Kubie to Bawang's face: first with the burlap bag, then with the back of his hand. Each HIT was preceded by various kinds of synchronous BEATING by the two. The degree of their attunement to each other is revealed markedly in the last bout. Kubie raised a hand, but Bawang, anticipating the gentle нाт, put her hands up to her face to block it. In counter, Kubie gently hit Bawang with his other hand before desisting - leading Bawang to respond with a broad play face.

Another challenge for traditional approaches to ape gesture is that in these interactive displays, a gesturer, in performing a sequence, might actually be encouraged to continue his or her performance, not cease it, when the recipient inserts their own gestures or other contributions. In Example 2, Kubie and Zura gestured back and forth with each other for the entire session, apparently satisfied, but without any evident goal related directly to contact for mating or play. Likewise, humans certainly do not always cease talking when they have successfully communicated with a partner; rather, they are likely to expand the discussion (and see Fröhlich et al., 2016b, for recent work on chimpanzee and bonobo turntaking sequences). The idea that gestures in such episodes are 'successful; or 'unsuccessful,' as some researchers propose, does not seem to fit. If the concept of success applies, it is simply in prolonging the two gorillas' social connection.

\subsection{Display, music and dance}

The display sequences of great apes appear to us to be inseparably connected to music and dance in the course of hominid evolution. One readily apparent resemblance is, of course, in the sonic, percussive actions that are an essential part of the displays. Fitch (2006) defined instrumental music as "the use of the limbs or other body parts to produce structured, communicative sound, possibly using additional objects" (p. 183). Similarly, Cross (2007) emphasized the motor dimension of music, noting "that the structure of its sonic patterns may be as much determined by the actions that produce them as by any abstract considerations of sonic design" (p.154). According to this production-minded perspective on music, Fitch (2012) suggested that drumming in African great apes, on the body and other objects, is perhaps the best example in mammals of instrumental music. Indeed, the gorillas in our examples displayed considerable creativity in their sound making with different "instruments," ranging from their own bodies, to their partner's bodies, to various objects and surfaces afforded by the environment. Our examples also show how the percussive actions of displays are composed into structures that involve repetition and variation of thematic elements. Gorillas put their percussive instinct to use in extensive recombinations and in ever new situations socially, structuring new and original material.

This innovation and variation in structure calls to mind Dissanayake's (2009) suggestion that the first music might have been "vocal, visual and kinesic ordinary behaviours altered: simplified or formalized, repeated, exaggerated, elaborated ... making them not ordinary" (p. 24). The continuous variation, restructuring and incorporation of various objects that takes place in display sequences demonstrate such a process of taking ordinary actions and modifying them into "not ordinary" sequences. Moreover, no two display sequences, even by the same individual using the same gestures, are exactly alike, varying as they do with the social situation and environmental affordances. The existence of individual style is important for musicians and dancers, and in ape display.

Bringing music and dance into the discussion allows us to make more sense out of the unclear 'meaning' of play and display gestures (cf, Hobaiter and Byrne, 2014). As Cross (2007) stated, "Ambiguity, or open-endedness in meaning, of music can be thought of as affording conceptual and social spaces within which individual and collective imaginings can take place

The potential for music-like activities to entrain collective behaviour, together with their ambiguity, provides a means whereby groups can coordinate their interaction within a framework that allows the meaning of any musical act to vary from participant to participant" (p. 157). Cross further observed that musical behaviors are not just active, but interactive. We once again note how, in Example 3, Kubie and Zura interacted in sound, whether in visual contact or not. Their interaction shows how the sought-after response or 'goal' of a sequence could simply be a similar answering sequence by another gorilla rather than some functional behavioral act. The phrase "playing off of each other" comes to mind, as in human improvisatory dialogue, musical or otherwise. 


\section{Conclusion}

Our study demonstrates a potential avenue to move beyond "meaning" in the study of great ape gesturing. Our detailed, more qualitative approach has, we argue, enabled us to uncover patterns in ape gesture sequences that have not previously been appreciated by many researchers. Previous studies of ape gesture sequences have failed to find a satisfactory unifying theory about why apes compose sequences. We suggest that there is no single answer. As we have shown through our series of examples, the great apes gesture with their bodies for different functions. One is for directive, tactile communication, often iconic, used to guide a partner's movement and attention. A second function is the performance of creative, structured, playful and often interactive, percussive displays. Elsewhere we have proposed that the iconic gesturing of great apes indicates that they share an important capacity for the evolution of human language (Perlman et al., 2012; Tanner and Byrne, 1996). Here, we suggest that in the gesture sequences of their creative, percussive displays, we may find homology to music and dance.

\section{Acknowledgements}

For improving the present paper we greatly appreciate the suggestions of two anonymous reviewers and one of the editors of the volume, Slawomir Wacewicz. We are grateful also to Barbara J. King for comments on an earlier version of this paper. The first author is indebted to Robert M. Fagen for conversation and collaboration over years on an early unpublished paper titled "Danceplay", a project that laid the groundwork for some of our current thoughts. A workshop in Los Angeles in 2014, "Action, Vision and Language and their Brain Mechanisms in Evolutionary Relationship," organized by Michael A. Arbib, was a catalyst for again thinking about the relationship of ape display to elements of music and dance; we appreciated the opportunity to present some of these thoughts at that workshop.

\section{References}

Byrne, R.W., 2016. Evolving Insight. Oxford University Press, Oxford.

Call, J., Tomasello, M., 2007. The Gestural Communication of Monkeys and Apes. Erlbaum, Mahwah, NJ.

Cartmill, E., Byrne, R.W., 2007. Orangutans modify their gestural signaling according to their audience's comprehension. Curr. Biol. 17, $1345-1348$.

Cross, I., 2007. Music, science and culture. Proc. Br. Acad. 147, 147-165.

Dissanayake, E., 2009. Root, leaf, blossom or bole: concerning the origin and adaptive function of music. In: Malloch, S., Trevarthen, C. (Eds.), Communicative Musicality. Oxford University Press, Oxford, pp. 17-30.

Fagen, R., 1981. Animal Play Behavior. Oxford University Press.

Fitch, W.T., 2006. The biology and evolution of music: a comparative perspective. Cognition 100, 173-215.

Fitch, W.T., 2012. The biology and evolution of rhythm: unravelling a paradox. In: Rebuschat, P., Rohmeier, M., Hawkins, J.A., Cross, I. (Eds.), Language and Music as Cognitive Systems. Oxford University Press, Oxford, pp. 73-95.

Fouts, R., Mills, S., 1997. Next of Kin: My Conversations with Chimpanzees. William Morrow, New York.

Fröhlich, M., Wittig, R.M., Pika, S., 2016a. Should I stay or should I go? Initiation of join travel in mother-infant dyads of two chimpanzee communities in the wild. Anim. Cogn. 19, 483-500.

Fröhlich, M., Kuchenbuch, P., Muller, G., Fruth, B., Furuichi, T., Wittig, M., Pika, S., 2016b. Unpeeling the layers of language: bonobos and chimpanzees engage in cooperative turn-taking sequences. Sci. Rep. 6, 25887.

Genty, E., Breuer, T., Hobaiter, C., Byrne, R.W., 2009. Gestural communication of the gorilla (Gorilla gorilla): repertoire, intentionality and possible origins. Anim. Cogn. 12, 527-546.

Genty, E., Byrne, R.W., 2010. Why do gorillas make sequences of gestures? Anim. Cogn. 13, 287-301.

Goodall, J., 1986. The Chimpanzees of Gombe: Patterns of Behavior. Harvard University Press, Cambridge.

Greenfield, P.M., Lyn, H., Savage-Rumbaugh, E.S., 2008. Protolanguage in ontogeny and phylogeny: combining deixis and representation. Interact. Stud. 9 (1), $34-50$.

Hobaiter, C., Byrne, R.W., 2011. Serial gesturing by wild chimpanzees: its nature and function. Anim. Cogn. 14, 826-838.

Hobaiter, C., Byrne, R.W., 2014. The meanings of chimpanzee gestures. Curr. Biol. 24 (14), 1596-1600.

Johnson, C., 2010. Observing cognitive complexity in primates and cetaceans. Int. J. Comp. Psychol. 23, 587-624.

King, B.J., 2004. The Dynamic Dance. Harvard University Press, Cambridge, MA.

Leavens, D.A., Hostetter, A.B., Wesley, M.J., Hopkins, W.D., 2004. Tactical use of unimodal and bimodal communication by chimpanzees, Pan troglodytes. Anim. Behav. 67, 467-476.

Leavens, D.A., Russell, J.L., Hopkins, W.D., 2005. Intentionality as measured in the persistence and elaboration of communication by chimpanzees (Pan troglodytes). Child. Dev. 76 (1), 291-306.

Leavens, D.A., Rusell, J.L., Hopkins, W.D., 2010. Multimodal communication by captive chimpanzees (Pan troglodytes). Anim. Cogn. 13, 33-40.

Liebal, K., Call, J., Tomasello, M., 2004. Use of gesture sequences in chimpanzees. Am. J. Primatol. 64, 377-396.

Loizos, C., 1966. Play in mammals. In: Jewell, A. (Ed.), Play, Exploration and Territory in Mammals. Academic Press, London, pp. 1-9.

McNeill, D., 2012. How Language Began: Gesture and Speech in Human Evolution. University of Chicago.

Miles, L., 1990. The cognitive foundations for reference in a signing orangutan. In: Parker, S., Gibson, K. (Eds.), "Language" and Intelligence in Monkeys and Apes. Cambridge University Press, Cambridge, pp. 511-539.

Parnell, R., Buchanan-Smith, H., 2001. An unusual social display in gorillas. Nature 412 (6850), p. 294.

Patterson, F., Linden, E., 1981. The Education of Koko. Holt, Rinehart, and Winston, New York.

Perlman, M., Clark, N., Tanner, J.E., 2014. Iconicity and ape gesture. In: Cartmill, E.A., Roberts, S., Lyn, H., Cornish, H. (Eds.), The Evolution of Language: Proceedings of the 10th International Conference (EVOLANG10). World Scientific, New Jersey, pp. 236-243.

Perlman, M., Clark, N., 2015. Learned vocal and breathing behavior in an enculturated gorilla. Anim. Cogn. 18, 1165-1179.

Perlman, M., Gibbs Jr., R.W., 2013. Pantomimic gestures reveal the sensorimotor imagery of a human-fostered gorilla. J. Ment. Imag. 37, 73-96.

Perlman, M., Tanner, J.E., King, B.J., 2012. A mother gorilla's variable use of touch to guide her infant: insights into iconicity and the relationship between gesture and action. In: Pika, S., Liebal, K. (Eds.), Current Developments in Primate Gesture Research. John Benjamins Publishing Company, Amsterdam, pp. 55-71.

Roberts, A.I., Vick, S., Buchanan-Smith, H.M., 2013. Communicative intentions in wild chimpanzees: persistence and elaboration in gestural signaling. Anim. Cogn. 16, 187-196.

Scally, A., Dutheil, J.Y., Hillier, L.W., Jordan, G.E., Goodhead, I., Herrero, J., Hobolth, A., Lappalainen, T., Mailund, T., Marques-Bonet, T., McCarthy, S., Montgomery, S. H., Schwalie, P.C., Tang, Y.A., Ward, M.C., Xue, Y., Yngvadottir, B., Alkan, C., Andersen, L.N., Ayub, Q., Ball, E.V., Beal, K., Bradley, B.J., Chen, Y., Clee, C.M., 
Fitzgerald, S., Graves, T.A., Gu, Y., Heath, P., Heger, A., Karakoc, E., Kolb-Kokocinski, A., Laird, G.K., Lunter, G., Meader, S., Mort, M., Mullikin, J.C., Munch, K., O'Connor, T.D., Phillips, A.D., Prado-Martinez, J., Rogers, A.S., Sajjadian, S., Schmidt, D., Shaw, K., Simpson, J.T., Stenson, P.D., Turner, D.J., Vigilant, L., Vilella, A.J., Whitener, W., Zhu, B., Cooper, D.N., de Jong, P., Dermitzakis, E.T., Eichler, E.E., Flicek, P., Goldman, N., Mundy, N.I., Ning, Z., Odom, D.T., Ponting, C.P., Quail, M.A., Ryder, O.A., Searle, S.M., Warren, W.C., Wilson, R.K., Schierup, M.H., Rogers, J., Tyler-Smith, C., Durbin, R., 2012. Insights into hominid evolution from the gorilla genome sequence. Nature 483, 169-175.

Schaller, G., 1963/1976. The Mountain Gorilla: Ecology and Behavior. The University of Chicago Press, Chicago.

Tanner, J.E., 1998. Gestural Communication in a Group of Zoo-Living Lowland Gorillas (Doctoral dissertation). University of St. Andrews, Scotland.

Tanner, J.E., 2004. Gestural phrases and exchanges by a pair of zoo-living lowland gorillas. Gesture 4 (1), 1-24.

Tanner, J.E., Byrne, R.W., 1996. Representation of action through iconic gesture in a captive lowland gorilla. Curr. Anthropol. 37 (1), $162-173$.

Tanner, J.E., Byrne, R.W., 1999. The development of spontaneous gestural communication in a group of zoo-living lowland gorillas. In: Parker, S.T., Mitchell, R.W., Miles, H.L. (Eds.), The Mentalities of Gorillas and Orangutans: Comparative Perspectives. Cambridge University Press, Cambridge, UK, pp. 211-239.

Tanner, J.E., Byrne, R.W., 2010. Triadic and collaborative play by gorillas in social games with objects. Anim. Cogn. 13 (4), $591-607$.

Tanner, J.E., Patterson, F., Byrne, R.W., 2006. Development of spontaneous gestures in zoo-living gorillas and sign-taught gorillas: from action and location to object representation. J. Dev. Process. 1, 69-103.

Tempelmann, S., Liebal, K., 2012. Spontaneous use of gesture sequences in orangutans: a case for strategy? In: Pika, S., Liebal, K. (Eds.), Current Developments in Primate Gesture Research. John Benjamins Publishing Company, Amsterdam, pp. 55-71.

Terrace, H.S., 1979. Nim. Knopf, New York.

Tinbergen, N., 1952. "Derived" activities; their causation, biological significance, origin, and emancipation during evolution. Q. Rev. Biol. 27, 1-32.

Tomasello, M., Call, J., Nagell, K., Olguin, R., Carpenter, M., 1994. The learning and use of gestural signals by young chimpanzees: a trans-generational study. Primates 35 (2), 137-154. 